where $\alpha$ is absorption coefficient of the liquid; $c$ is velocity of propagation of sound in the liquid; $R$ is radius of the cylindrical vessel; $H$ is height of the vessel ; $f$ is frequency ; $\eta$ is ordinary coefficient of viscosity (shear viscosity); $\rho$ is density of the liquid ; $A$ is a constant.

The first term of the right-hand side of this equation indicates the absorption in the liquid. The second term indicates the losses caused by friction along the walls and bottom of the vessel. The third term indicates the losses caused by radiation into the air from the liquid surface. The fourth term indicates the losses caused by conduction to the crystals attached to the bottom.

The third and fourth terms are small. Only the second term is important. This term is deduced in a manner analogous to the one in which the losses by friction of acoustical waves in tubes can be calculated ${ }^{4}$. Two assumptions are made : (1) the sound energy is distributed homogeneously in the vessel; (2) the walls of the vessel behave as rigid walls. The second assumption seems strange, for the material of the walls is aluminium, 1-2 mm. thick. However, it can be proved experimentally in a direct way, or by the ultimate validity of equation (1). For the same reason, too, the losses in the material of the wall itself are negligible. Moreover, the absorption coefficient of aluminium is small ${ }^{5}$.

As an experimental control, the absorption coefficient for water at $25^{\circ} \mathrm{C}$. has been determined for three frequencies, $750,1,010$ and $1,500 \mathrm{kc} . / \mathrm{s}$. , by measuring the reverberation time in aluminium vessels. Two vessels were available, both with $R=14 \mathrm{~cm}$. and $H=10 \mathrm{~cm}$. ; the walls were $1 \mathrm{~mm}$. and $2 \mathrm{~mm}$. thick respectively. The measured reverberation-time was independent of the thickness of the wall, as may be expected from equation (1). The results, with the corrections from equation (1), and the resulting value of $\alpha$ are given in the accompanying table.

Reverberation measurements in aluminium vessel flled with water of $25^{\circ} \mathrm{C}$.

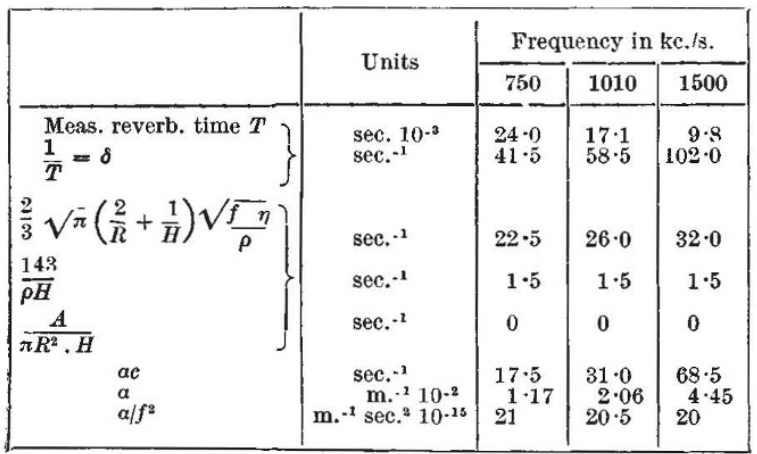

The correction terms are calculated as follow : $R=0.14$ m. ; $H=0.10 \mathrm{~m}$. ; $\eta=0.89 \times 10^{-3} \mathrm{~N}$ m..$^{-2}$ sec. ; $\rho=1,000 \mathrm{kgm} . \mathrm{m}^{-3} ; c=1,500 \mathrm{~m} \cdot \mathrm{sec}^{-1}$. The values found in this way show that $\alpha / f^{2}$ is independent of the frequency in this region. They correspond quite well with the values for $\alpha / f^{2}$ found by several investigators for higher frequencies ${ }^{1}(5 \mathrm{mc} . / \mathrm{s}$. and upwards).

In Fig. 2 the calculated and measured values for $\delta=1 / T$ are given for three vessels, with $R=14,10$ and $8 \mathrm{~cm}$. and $H=10,7 \cdot 2$ and $6 \mathrm{~cm}$. respectively, filled with water of $25^{\circ} \mathrm{C}$., as a function of the value

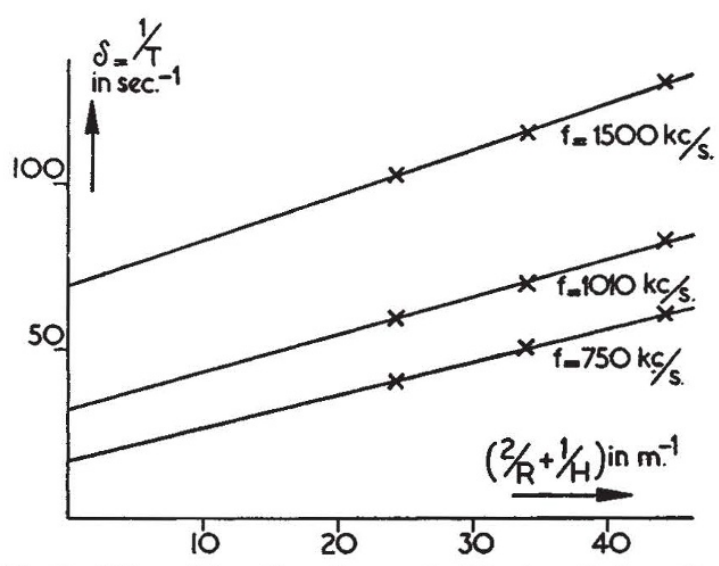

Fig. 2. Values of the attenuation constant (reciprocal of reverberation time) for vessels filled with water of $25^{\circ} \mathrm{C}$. for three

frequencies as function of the dimensions of the vessels.

$\longrightarrow$, calculated values. $\times$, measured values

of $\left(\frac{2}{R}+\frac{1}{\tilde{H}}\right)$ for the three vessels. The values are

calculated from equation (1) with $\alpha / f^{2}=21 \times 10^{-15}$ m..$^{1}$ sec. ${ }^{2}$. They agree quite well with the measured values, within the accuracy of the measurements ( $\sim 3$ per cent). It is clear that even in the small vessel of volume 1,200 c.c., the agreement is good enough to get results for the coefficient of water.

It seems likely that the condition of the inside of the walls is important (roughness, etc.). However, there is a simple method of getting quite reproducible results. The aluminium vessels (the same as are used for household purposes) were boiled with water, if they were new, and rubbed with a piece of cloth with water and alcohol before each measurement.

Air bubbles can give difficulties. That is why boiled distilled water was used for the measurements.

A full report will appear in Applied Scientific Research. The apparatus has already been described in the same periodical ${ }^{6}$.

${ }^{1}$ Pinkerton, J. M. M., Nature, 160, 128 (1947). Fox, F. E., and Rock, G., J. Acous. Soc. Amer., 12, 505 (1941).

${ }^{2}$ Knudsen, V., J. Acous. Soc. Amer., 3, 126 (1931).

${ }^{3}$ Meyer, E., and others, "Schallausbreitung im Wasser".

"Crandall, I. B., "Theory of Vibrating Systems and Sound", Appen-

dix A.
'Mason, W. P., and MeSkimin, H. J., J. Acous. Soc. Amer., 19, 764 (1947).

'Mulders, C. E., App. Sci. Res., B1, 149 (1948).

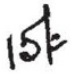

\section{EXPLOSIBILITY OF AMMONIUM NITRATE}

T $T$ has long been known that ammonium nitrate 1 can be made to explode in certain circumstances, and since thecatastrophe at Oppau in 1921, it has been recognjed that proper precautions should be takn Never Meless, there have recently been two cases, A Texar City and Brest respectively, in which sho load with ammonium nitrate of American moufactur have caught fire and eventually exploded with violence. At Oppau the catastrophe was ascribed to the fact that charges of explosive were used to break up the mass, which had set hard; but in the recent cases the explosions were evidently due to heat alone. As ammonium nitrate is being used on a very large scale as a fertilizer, the British 
Government appointed a working party under the chairmanship of the chief inspector of explosives to investigate the matter experimentally, and a report* has now been issued. The experimental work was carried out mostly by the officers of the chief superintendent of armament research ; but officers of other departments also collaborated.

Ammonium nitrate is liable to cake into a hard mass soon after manufacture; so as to keep it in a free-running condition the American product is mixed with about 1 per cent of a hydrocarbon resembling 'Vaseline' and 5 per cent of kaolin. It is packed in 100-lb. paper bags of six-ply, two of which are coated with an asphaltic composition. On the other hand, the British material for agriculture is a practically pure synthetic product (ammonium nitrate 99.8 per cent; water about 0.15 per cent). It is packed in steel drums containing $4 \mathrm{cwt}$. each.

Laboratory experiments showed that a mixture of the composition of the American product ignites more readily than pure ammonium nitrate. This was confirmed by field trials in which the two products were heated under the same conditions in artillery shells. Not only did the American material decompose more quickly and at a lower temperature than the British, but also it was liable to explode violently, whereas the British product either did not explode at all, or only did so mildly. When heated in steel tubes $2 \mathrm{ft}$. long by $0.45 \mathrm{in}$. in diameter by $0.08 \mathrm{in}$. thick, the British product burst the tube only at the end where it was actually heated, whereas that from America burst it from end to end, showing that explosion had spread to the unheated portion.

Trials on a larger scale were then carried out at the island of Dune in Heligoland Bay with British ammonium nitrate. Seventy tons of it were stacked in drums in an underground bunker of reinforced concrete, and a fire was lit of some fifteen tons of a mixture of wood and ammonium nitrate. There was no explosion, although there was evidence that the interior of the bunker had been raised to a red heat.

Similar trials were carried out in two steel lighters (or barges). In one case the ammonium nitrate was in drums and in the other in bags. In neither case was there an explosion, although the recorded temperature in the space above the nitrate rose to $500^{\circ}$ C., and there was evidence that part of it attained a red heat. Samples of the atmosphere in the bunker and lighters were taken during the fires by an automatic apparatus. Their analysis indicated that much of the ammonium nitrate had been decomposed by the heat into oxygen, nitrogen and oxides of nitrogen.

The trials, therefore, indicate that when pure ammonium nitrate is heated it decomposes, and the pressure developed may burst the container; but even with strong confinement explosion does not extend beyond the material actually heated. Although it cannot be stated with absolute certainty that in a large consignment stored in bulk self-confinement might not lead to a true explosion of the mass in some exceptional circumstances, the results obtained show that British ammonium nitrate under normal conditions of storage and transport is safe.

Admixture of combustible material, such as paper and wood, in pieces of visible size did not cause

- Report on Experimental Investigations on the Safety in Storage and Transport of Ammonium Nitrate. By W. A. Bailey. 12 pp. +11 pp. of appendixes +16 pp. of illustrations. explosion in mass. Therefore safety does not appear to be threatened by the use of paper bags or linings of waxed paper to the steel drums, although the use of such inflammable material is open to criticism.

A small amount, such as 1 per cent, of hydrocarbon mixed intimately with ammonium nitrate alters its behaviour when strongly heated. With strong confinement the decomposition becomes explosive, and the explosion may be propagated throughout the mass. Large-scale experiments were not, however, carried out with this mixture.

ARThur Marshall

\section{0 \\ VALVE PORT DESIGN OF COMPRESSION-IGNITION ENGINES}

ONE limitatiop on the maximum power developed by an internd an woustion engine is the volumetric efficienc, Whech is a function of so many variables that the $r$ interrelation is unfortunately not always und stood. However, in a paper read before the Inst uton of Mechanical Engineers and entitled "Whe Tnfluence of Valve Port Design on the Volunffurid - Ifficiency of the Compression-Ignition Ev ine", Mr. C. B. Dicksee succeeds in explaining clearly how these factors affect volumetric efficiency, and discusses the results of experiments carried out to compare the pressure loss in various forms of venturi and straight-sided inlet ports.

The practical results of the experiments are perhaps unexciting, confirming, as they do, what has long been known and practised. Confirmatory and quantitative evidence is, however, always useful, and one particularly valuable result is that those ports which have the best performance under steady-flow conditions are found also to show the smallest losses at full load over the highest speed range. This, of course, means that the effectiveness of a port may be determined by testing it on a simple blowing rig.

The experiments consist of three series of tests, each with some six different shapes of port, and performed under steady-flow, motoring and full-load conditions. In the first series a marked improvement in the pressure loss when using the venturi is found, provided the valve seat is of adequate diameter. The other series confirm that under practical conditions it is valve-seat diameter, only, that is of importance, passage shape having a negligible effect, since its influence is so small compared with that of other factors which arise under running conditions. Other things being equal, the venturi is preferred, as it provides much-needed space in the cylinder head for the injector.

The greatest interest of the paper lies not so much in the experiments as in the comparison of petrol. engine and Diesel breathing requirements, the description of the induction process in the latter and the clear exposition, helped by some excellent light. spring diagrams, of the various complicating factors which influence volumetric efficiency. It is refreshing to find an expert who does not lay the burden of all unexplained phenomena, which transpire during the exhaust and early induction period, on the shoulders of those convenient scapegoats, exhaust pressure waves. Particularly sound is the explanation of why the motoring volumetric efficiency should be considerably higher than full-load volumetric efficiency 